\title{
One episode, two lenses
}

\section{A reflective analysis of student learning with computer algebra from instrumental and onto-semiotic perspectives}

\author{
Paul Drijvers • Juan D. Godino • Vicenç Font • \\ Luc Trouche
}

Published online: 7 July 2012

(C) The Author(s) 2012. This article is published with open access at Springerlink.com

\begin{abstract}
A deep understanding of students' learning processes is one of the core challenges of research in mathematics education. To achieve this, different theoretical lenses are available. The question is how these different lenses compare and contrast, and how they can be coordinated and combined to provide a more comprehensive view on the topic of study. To investigate this, one single episode is analyzed with two theoretical lenses, the instrumental genesis perspective and the onto-semiotic approach. The results from this joint analysis provide a rich view on the observed phenomena and help to identify the affordances and constraints of each of the two theoretical approaches and to articulate them. This way, the networking of theories proves to affect theoretical advancements.
\end{abstract}

Keywords Digital technology · Instrumental genesis · Mathematics education · Networking of theories · Onto-semiotic approach

\footnotetext{
P. Drijvers $(\bowtie)$

Freudenthal Institute for Science and Mathematics Education, University of Utrecht, PO box 85170, 3508 AD Utrecht, the Netherlands e-mail: p.drijvers@uu.nl

J. D. Godino

Faculty of Education, University of Granada, Campus de Cartuja, 18071 Granada, España e-mail: jgodino@ugr.es

\section{Font}

Departament de Didàctica de les Ciències Experimentals i la Matemàtica Campus Vall d'Hebron, Universitat de Barcelona, Passeig de la Vall d'Hebrón, 171, 08035 Barcelona, Spain e-mail: vfont@ub.es

L. Trouche Institut français de l'Éducation, École Normale Supérieure de Lyon, 15 parvis René-Descartes, BP 7000, 69342 Lyon cedex 07, France e-mail: Luc.Trouche@ens-lyon.fr
} 


\section{Introduction}

A deep understanding of students' learning processes is one of the core challenges of research in mathematics education. To contribute to this goal, subtle analyses of the complex richness of mathematical activities and learning behaviours are essential. Usually, such analyses are guided by specific theoretical lenses, which each offer their own, particular view on the phenomenon under consideration. However, each theoretical lens provides a specific, and as a consequence also limited, view on the data that it considers relevant. Therefore, it is interesting to compare the results of analyses of the same phenomenon from the perspective of different theoretical approaches, and to investigate if they lead to complementary or even conflicting findings. Such a comparison not only enriches the analysis and the understanding of the phenomenon; through the articulation of the different approaches it may also affect theoretical advancements in the field, and lead to a better understanding of the affordances and constraints of each of the theoretical frameworks involved.

The idea to compare and contrast different theories is not new (e.g., see Maier \& Steinbring, 1998; Even \& Schwarz, 2003), but it still is a topic under consideration today (e.g., see Lagrange \& Psycharis, 2011). Lagrange, Artigue, Laborde and Trouche (2003), in their research literature survey, show the interest of considering a variety of dimensions for understanding the complexity of integrating technology in mathematics teaching. More recently, the issue of networking different theoretical frameworks has been addressed extensively in the work of the CERME Working Groups on "Different Theoretical Approaches and Perspectives in Mathematics Education Research" (Prediger, Arzarello, Bosch \& Lenfant, 2008). In Section 2.1 the results of these research activities will be addressed in more detail.

As an example, this paper describes an exemplary case study on comparing and contrasting two theoretical frameworks for mathematics education: the Theory of Instrumental Genesis (TIG) and the Onto-Semiotic Approach to mathematical knowledge and instruction (OSA). Although comparing and contrasting these theoretical perspectives could be done by considering their respective descriptions and assumptions, we prefer to put them into action simultaneously as didactical tools in a joint analysis of the teaching and learning phenomena that appear in the same empirical data. While doing so, we want to better understand the scope and power of each of these theoretical frameworks, as well as to explore their possible complementarities. As such, it is a concrete case study on the networking of two theoretical lenses, which explains the article's title.

In addition to the targeted better understanding of the case under consideration, this networking theory case description is relevant for several reasons. First, even if some elements of networking theory have been used in the field of digital technology in mathematics education (e.g., Artigue, Cerulli, Haspekian \& Maracci, 2009), a full networking theory approach in this domain has been absent so far. Second, a new aspect in the networking approach presented here is the use of Radford's (2008) description of three essential elements of theory, namely principles, methods, and paradigmatic research questions. In Section 7, this view will prove to be fruitful. Third and final, this case shows the interest of including theories with different scopes in the networking. In this case, the articulation of a basically cognitive theory with a particular interest in the use of (digital) artefacts (TIG) with a more general didactics theory (OSA) is addressed. The two theories, both well-known in the field of mathematics education (e.g., see Guin \& Trouche, 1999; Godino, Batanero \& Font, 2007), are different in their aims and frameworks, which make the comparison and contrasting particularly interesting.

In line with the difference of scope of the two theoretical approaches involved, the case we selected needs to meet the focus of the most specific one of the two, the TIG. The 
challenge of this enterprise was to investigate whether the more general character of OSA would apply to this specific case, and would contribute to the TIG lens. The choice for TIG and OSA was also guided by the authors' expertise.

In the next section, we elaborate the central questions of this paper and outline its theoretical framework. Then, the methodological and methodical considerations and research context are sketched. Sections 4 and 5 contain the analysis of the episode presented in the Appendix from TIG and OSA perspective, respectively. In sections 6 and 7, the two analyses and the two frameworks are compared and contrasted. Finally, in Section 8 we present the article's conclusion.

\section{Theoretical framework}

The central question addressed in this paper is: what does networking instrumental genesis and onto-semiotic approaches as lenses for didactical analysis add to the results of the separate analyses and how can the results be compared and contrasted? As an agenda beyond this question, we expect to experience the benefits and pitfalls of this joint analysis of one single and short episode for the purpose of theoretical reflection and advancement.

In this section we first frame the analysis by the notion of networking theories; next, we outline the two lenses at stake, the instrumental genesis and onto-semiotic approaches.

\subsection{Networking of theories}

Bikner-Ahsbahs and Prediger (2010) make a plea for exploiting theoretical diversity as a resource for richness and consider this diversity as a challenge and starting point for further theoretical development through networking theories. The authors introduce the notion of connecting strategies for strategies that put theories into relation. Prediger, Bikner-Ahsbahs and Arzarello (2008) describe different connecting strategies and methods for articulating theories, which range from completely ignoring other theoretical perspectives on the one extreme end, to globally unifying different approaches on the other. As intermediate strategies, the authors mention the need for making understandable one's own perspective and for understanding other perspectives, and the strategies of comparing and contrasting different approaches, coordinating and combining perspectives, and achieving local integration and synthesis. We now briefly address different networking strategies as far as we consider them relevant for the case study presented in this paper.

As an important first phase in networking theories, we acknowledge the need to really understand other theories, and to make understandable one's own approach, both not only by speaking about theoretical foundations and concepts, but also by discussing concrete examples and cases. Even if this sounds very straightforward, this first step is not an easy one. Still, we see mutual understanding as a prerequisite for further networking. A next step in networking may consist of comparing and contrasting theories, to identify similarities and differences, possible connections as well as complementary aspects. The aim of this strategy, in our case, is not to put the two approaches in a competition, but rather to see if the results from both analyses shed new lights on the phenomenon under consideration. This brings us to the final networking strategy at stake, namely coordinating and combining the two lenses. As Bikner-Ahsbahs and Prediger (2010) phrase it, "the strategies of coordinating and combining are mostly used for a networked understanding of an empirical phenomenon or a piece of data," which is exactly what we want to achieve in this case study.

In this study, we therefore apply the notion of networking theories with a focus on mutual understanding of theoretical lenses, on comparing and contrasting, and on coordinating and 
combining, on the one hand to reach for a better understanding of the learning and teaching phenomena under consideration, and on the other hand to further explore the process of networking theories.

\subsection{The theory of instrumental genesis}

The theory of instrumental genesis attributes a major role to artefacts that mediate the human's activity for carrying out a task. Learning, then, is seen as the development, driven by the necessity of activity, of techniques for using artefacts and of cognitive schemes that integrate pragmatic and epistemic knowledge. For the sake of the analysis that follows, we choose to present TIG here in terms of dualities, even if the different edges of these dualities will turn out to be different faces of the same coin rather than extreme counterparts.

A first and central duality in TIG is the distinction between artefact and instrument (Rabardel, 2002). An artefact is an-often but not necessarily physical-object that is used to achieve a given task. It is a product of human activity, incorporating both cultural and social experience. Think of a hammer, a piano, a calculator, or a dynamic geometry system on your PC. What exactly is the artefact in a given situation is not always clear: for example, in the case of dynamic geometry software, it is a matter of granularity if one considers the software as one single artefact, or if one sees it as a collection of artefacts, such as the construction artefact, the measurement artefact, the dragging artefact, and so on (Leung, 2008). The way an artefact is used is nontrivial. As long as we have no idea about what letters stand for, a pen is a useless artefact for writing. As soon as we learn to write, the pen becomes more than an artefact for drawing, and changes into an artefact that we also use for writing. Together with the developing skills, the pen becomes an instrument for writing. This brings us to the psychological construct of the instrument being more than an artefact. Following Rabardel (2002), we speak of an instrument if a meaningful relationship exists between the artefact and the user for a specific type of task. The in many cases ongoing, nontrivial and time-consuming process of an artefact becoming part of an instrument in the hands of a user is called instrumental genesis. This general theory has been applied to the case of mathematics learning with artefacts (such as calculators, see Guin \& Trouche, 1999), where the user is a student.

A second duality in instrumentation theories is the instrumentation-instrumentalisation duality. During the instrumental genesis, a bilateral relationship between the artefact and the user is established: while the student's knowledge guides the way the tool ${ }^{1}$ is used and in a sense shapes the tool (this is called instrumentalisation), the affordances and constraints of the tool influence the way the student carries out a task and the emergence of the corresponding conceptions (this is called instrumentation). The dual nature of instrumentation and instrumentalisation within instrumental genesis comes down to the student's thinking being shaped by the artefact, but also shaping the artefact (Hoyles \& Noss, 2003). If we take the graphing calculator as an exemplary artefact, its menu option "Calculate Intersect" solves equations by calculating coordinates of intersection points of graphs. On the one hand, this guides the students' thinking towards seeing solutions as intersection points (instrumentation). If, on the other hand, a student programs the calculator so that it will give solutions in exact, radical forms, this would be an example of instrumentalisation (Drijvers, 2003; Trouche \& Drijvers, 2010).

A third duality, and probably the most important in this paper, is the scheme-technique duality, which addresses the relationships between thinking and gesture. According to Vergnaud (1996), a scheme is an invariant organization of activity for a given class of

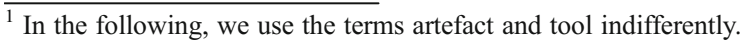


situations. More informally, a scheme is a more or less stable way to deal with specific situations or tasks, guided by developing knowledge. When using an artefact, a student develops a scheme of instrumented action (Trouche, 2000), for example a scheme of equation solving using a graphing calculator. Such a scheme is made of gestures for using the given artefact, rules of action, and conceptual elements, both guiding the activity, and developed by this activity. The development of such schemes is the heart of instrumental genesis. In this view, an instrument consists of part of the artefact mobilized by a user for achieving a type of task and the scheme that $\mathrm{s} /$ he develops in this activity (Verillon \& Rabardel, 1995). Instruments do not live in isolation: often, different types of tasks are achieved with (parts of) the same artefact. In such processes, different schemes develop, so different instruments are built. The question of developing a coherent system of instruments is thus crucial (Rabardel, 2002).

The anthropological theory of didactics (Chevallard, 1999) describes the relationships between gesture and thinking in terms of praxis (composed of tasks and techniques, the latter being understood as "a way of doing" a given task) and logos (discourse justifying techniques, and theories as the "raisons d'être" of these techniques). It is acknowledged, though, that techniques cannot be separated from thinking. Artigue notes that the word "technique" has to be given a wider meaning than what is usual in educational discourse: "A technique is a manner of solving a task and, as soon as one goes beyond the body of routine tasks for a given institution, each technique is a complex assembly of reasoning and routine work" (Artigue, 2002, p. 248). In this perspective, techniques are seen as carriers of knowledge and have both pragmatic and epistemic value (Lagrange, 2000).

In this paper, we take a practical stance: we see techniques as the observable part of the students' work on solving a given type of tasks (i.e., a set of organized gestures) and schemes as the cognitive foundations of these techniques that are not directly observable, but can be inferred from the regularities and patterns in students' activities. In this sense, gesture and thinking are closely related, and techniques are seen as reflecting the schemes.

Whereas instrumental genesis focuses on the learner, TIG is complemented by the notion of instrumental orchestration, which refers to the teacher's intentional and systematic organisation and use of the various artefacts available in a learning environment in a given mathematical task situation, in order to guide students' instrumental genesis (Drijvers, Doorman, Boon, Reed \& Gravemeijer, 2010; Trouche, 2004).

\subsection{The onto-semiotic approach}

The onto-semiotic approach to mathematical knowledge and instruction (OSA) is a comprehensive general theoretical framework that provides specific conceptual tools for the didactical analysis of different facets involved in the teaching and learning of mathematics (Godino \& Batanero, 1998; Godino et al., 2007; Godino, Font, Wilhelmi \& Lurduy, 2011; Font, Godino \& Gallardo, 2012). The OSA assumes mathematical knowledge has a socio-epistemic dimension, since knowledge is indissolubly linked to the activity in which the subject is involved and depends on the institutional and social context in which it is embedded.

Mathematical activity plays a central role in the OSA and is modelled in terms of systems of practices. It is important to distinguish between human behaviour (understood as the apparent and observable behaviour of individuals) and human action, which has an aim. The OSA conceives a mathematical practice as a sequence of actions, regulated by institutionally established rules, oriented towards a goal (usually solving a problem). Since practices are carried out in time, a way to describe them is through the narrative description of the subject's actions and the rules in use. 
Objects play an important role in OSA. In ordinary language the word "object" refers to material, tangible or real things. In the philosophy of mathematics, the term "mathematical object" usually refers to abstract objects such as classes of entities, propositions or relationships. However, in the OSA ontology, "object" is used in a broad sense for any entity which is in some way involved in mathematical practice and can be identified separately. If we consider, for example, the objects involved when carrying out and evaluating a problem solving practice, we can identify the use of different languages (verbal, graphic, symbolic, ...). These languages are the ostensive part of a series of concepts and definitions, propositions and procedures that are involved in argumentation and justification of the problem solution. These six objects (problems, languages, concepts/definitions, propositions, procedures and arguments) are considered as primary objects and together form configurations of primary objects (Fig. 1). The term configuration is used to designate a heterogeneous set or system of objects related to each other. These configurations of objects can be seen from the personal and from the institutional perspective, which leads us to distinguish cognitive (personal) and epistemic (institutional) configurations of primary objects. Hence, an epistemic configuration is the system of primary objects that are from the institutional point of view involved in the mathematical practices carried out to solve a specific problem.

What is the nature of the primary objects? We feel that the nature of problems, linguistic elements, arguments and propositions will be clear to the reader, but this may not be the case for the other primary objects (concepts/definition and propositions). In the OSA, and in accordance with Wittgenstein's philosophy of mathematics, concepts/definitions and propositions are conceived of as grammatical rules (Wittgenstein, 1953).

In mathematical practices, the above mathematical primary objects appear in different ways, which are characterized by the following dualities: personal/institutional, unitary/systemic, expression/content, ostensive/non-ostensive and extensive/intensive. In terms of processes, these dualities, as well as the primary objects themselves, lead

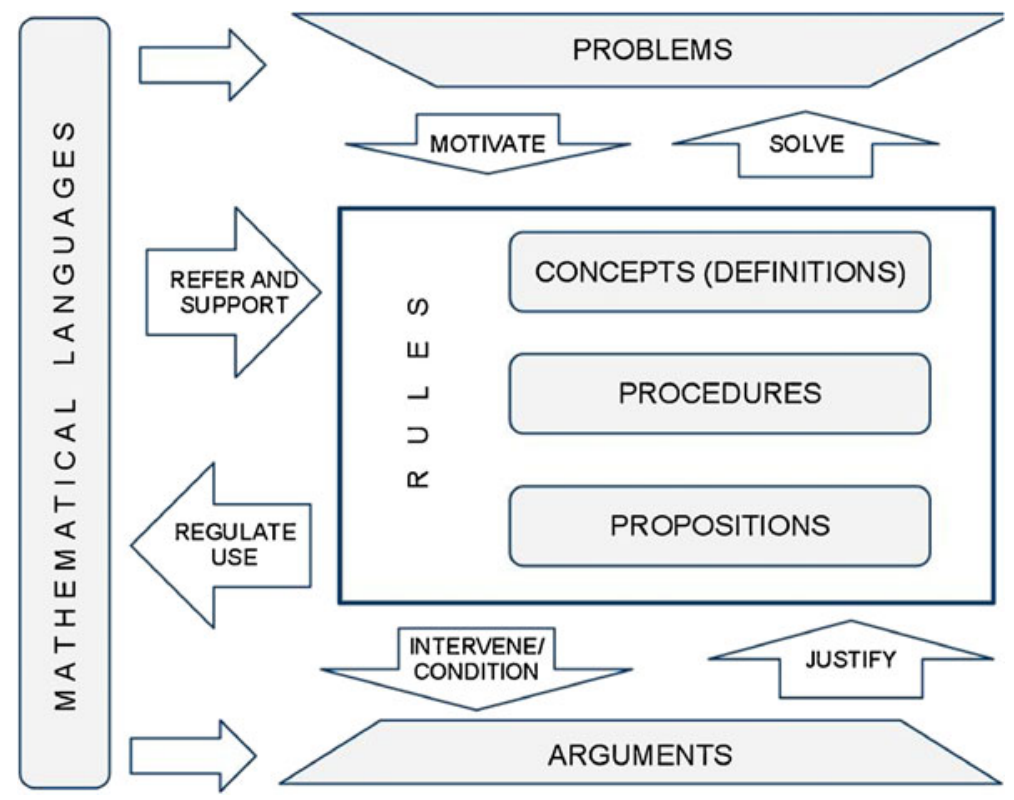

Fig. 1 Configuration of primary objects involved in mathematical practices 
to the following pairs of processes that intervene in mathematical practices (Godino et al., 2011):

- institutionalisation-personalisation;

- generalisation-particularisation;

- analysis/decomposition-synthesis/reification;

- materialisation-idealisation;

- expression/representation-signification.

As in mathematics education in general, meaning is a key notion in the onto-semiotic approach, and is basically conceived of in two ways. First, meaning is conceived of through the semiotic function. According to Hjelmslev (1943) and Eco (1976) a semiotic function is the correspondence or dependency relationship between an antecedent (expression, signifier) and a consequent (content, signified or meaning) established by a subject (person or institution) according to a rule, habit or criterion. The content of the semiotic functions, and hence the meaning, can be personal or institutional, unitary or systemic, ostensive or non-ostensive object (Godino et al., 2007); it can be a definition, problem, procedure, argument, or a linguistic element. In agreement with Peirce's semiotics (1978), the onto-semiotic approach assumes that both the expression (antecedent of a semiotic function) and content (consequent of a semiotic function) may be any type of entity. Second, meaning can be understood in terms of usage. From this perspective the meaning of an object is understood by what can be done with it. This is a systemic perspective, in that it considers the meaning of the object to be the set of practices in which it plays a determining role. These two ways of understanding meaning complement each other, since mathematical practices involve the activation of configurations of primary objects and processes that are related by means of semiotic functions.

In OSA, a didactical configuration is the primary unit for didactical analysis. A didactical configuration aims at the teaching and learning of an epistemic configuration, which is the configuration of institutional mathematical objects put into action to solve the task. It includes students studying a mathematical task, using some technological and/or non-technological resources, interacting with the teacher and/or other students. A didactical configuration aims at the teaching and learning of an epistemic configuration. Every instructional process consists of a sequence of didactical configurations, named a didactical trajectory. Every didactical trajectory includes a cognitive trajectory for the students. The learning built throughout the process might be viewed as a set of cognitive configurations, that is the networks of objects emerging from or involved in the systems of personal practices that students carried out during the implementation of the epistemic configuration. Learning is understood as the student's appropriation of the intended institutional meaning, which entails the competence to carry out the institutional practices required to solve the tasks, as well as knowing and understanding the objects involved in them.

\section{Methodological and methodical considerations}

The authors of this paper consist of two researchers who are experienced in using the TIG framework in their research (the first and fourth author) and two researchers who have a substantial experience in using OSA (the second and third author). Each of the two "theory pairs" worked separately from the other for carrying out the initial analysis. In addition, two "cross-pair" face-to-face meetings were held. Further exchanges took place through email.

To carry out this case study of networking theories, a first step was to select a didactical episode to be analyzed. We agreed upon a short episode that originated from a study by the first author (Drijvers, 2003). As OSA has a wider scope than TIG, we decided to take data 
relevant for the more specific TIG theory as a point of departure. In principle, any data of an episode of teaching and learning mathematics may be analyzed with OSA tools.

The episode, which is described in more detail below and which is presented in the Appendix, was chosen because it included the use of technological tools, which is important for the application of TIG. Furthermore, this episode's data are quite extensive and include written work, audio and video recording, and calculator screen captures. Finally, the episode is rather short, which seems practical for the purpose of this somewhat explorative enterprise. The fact that the data stem from a study carried out by the first author provided him with more information than the others; to overcome this, we tried to share as much information as possible on the educational context of the episode, and the first author had to take a more distant research perspective while analyzing the data and to communicate eventual implicit knowledge that might play a role.

As a next step, each of the two pairs wrote an outline on the TIG and OSA framework, respectively, to summarise the core elements of their lenses and to start the process of understanding each other, and making understandable one's own approach. The final versions of these texts form the basis of the descriptions provided in sections 2.2 and 2.3.

Then, the two pairs of researchers analyzed this didactical episode, but each pair with its own theoretical lens. As a point of departure, it was decided to use the transcript, and not the original audio and video recordings, the audio being in Dutch and the video being of limited quality. The OSA team split up the transcript into units of analysis, which reflect the episode's sequence of didactic configurations in OSA terms.

Next, each of the pairs analyzed the didactical episode and described their findings. In a face-to-face meeting, these findings were exchanged and discussed which led to clearer and more accessible descriptions, as presented in sections 4 and 5, as well as to a first process of comparing and contrasting.

Finally, the processes of comparing and contrasting and of coordinating and combining were carried out in close but mainly distant collaboration, leading to a synthesizing analysis (see Section 6). Conclusions on the central question and on the outcomes of the study were also formulated. Overall, this process took a period of one year.

We now describe the episode in more detail. The case stems from a study by the first author on the use of computer algebra for the learning of the concept of parameter (Drijvers, 2003). It concerns an observation of two Dutch students working on a mathematical task in a class that is engaged in an experimental teaching sequence of fifteen 50-minute lessons. During the teaching sequence, students have a symbolic calculator (TI-89) at their disposal, both in school and at home. The two students, Maria and Ada, are middle to high achieving 16 year olds (grade 10) from the science stream of pre-university secondary education. Maria and Ada are cooperative students, who are seated next to each other in the back of the class. They agreed to be followed more closely than other pairs of students. They often work together as a pair, but they do have individual paper notebooks and calculators and sometimes follow their individual paths of thinking and working, even if they were asked to collaborate. As Maria is the more communicative of the two and therefore the student we want to observe in more detail, the screen of her calculator is projected behind them, so as to allow for video recording. Data consist of the students' paper-and-pencil work, video recordings of Maria's screen, audio recording of the students' dialogues, and interviews with the observer.

The episode consists of a 15-minute fragment, taken from two subsequent lessons, in which the students work on the task shown in Fig. 2. The task is in the final section "Using general solutions" of the teaching experiment textbook, designed for the occasion of this teaching experiment. ${ }^{2}$ As preliminary mathematical knowledge, the students know to apply

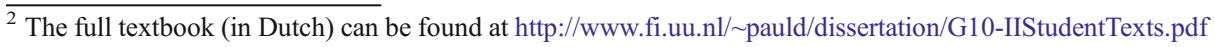




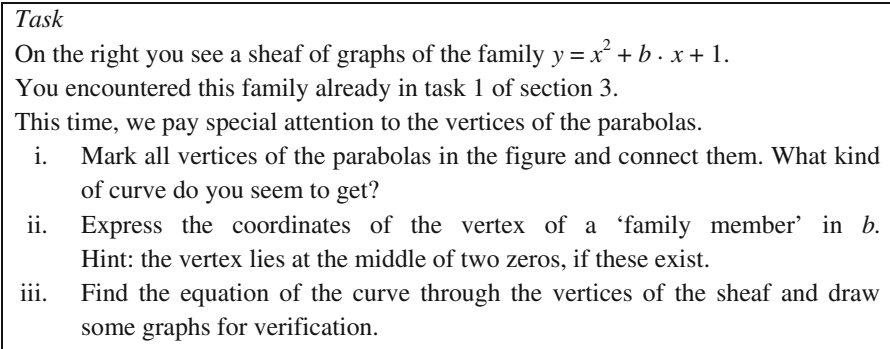

i. Mark all vertices of the parabolas in the figure and connect them. What kind of curve do you seem to get?

ii. Express the coordinates of the vertex of a 'family member' in $b$. Hint: the vertex lies at the middle of two zeros, if these exist.

iii. Find the equation of the curve through the vertices of the sheaf and draw some graphs for verification.

Fig. 2 Sheaf of graphs task

the formula for solving quadratic equations to concrete (non-parametric) cases. As preliminary technological knowledge, the students are able to draw graphs on the symbolic calculator, to solve non-parametric equations and to carry out numerical substitutions.

The final goal of this task which was new and difficult for these students, is to find $y=1-x^{2}$ as the equation of the parabola formed by the vertices of the family of parabolas. Task $\mathrm{i}$ aims at a graphical orientation in the figure provided with the task. Task ii suggests expressing the zeros of the parabola in terms of the parameter $b$, as a means to find that the first coordinate of the vertex is $-b / 2$. Of course, completing the square would also be a correct way to get this result; however, this is not so prominent in Dutch curricula, and not so easy to carry out with the symbolic calculator. In part iii, the aim is to eliminate $b$ to get the desired equation. The most direct way to achieve this is to replace $b$ by $-2 x$ in the general equation $y=x^{2}+b \cdot x+1$.

The episode's full transcript can be found in Appendix 1. Maria is very expressive and willing to talk. Also, she is seated in a position closer to the centre of the classroom. The class teacher is walking around in the classroom, while the students are working, but as the observer is positioned close to Ada and Maria, and that corner of the classroom is quite full with video equipment, the teacher is rarely near to this pair of students. Therefore, the observer - who is this paper's first author-participates as a teacher, and in the transcript is labelled as such. He regularly interacts with Maria and these interactions are important for Maria's progress.

\section{Analysis from the TIG perspective}

The first analysis of the case takes a TIG perspective. As the case presented in the Appendix concerns parts of two subsequent lessons, data are insufficient for a longitudinal analysis of the student's instrumental genesis. Therefore, we focus on techniques Maria uses, and try to infer from these techniques and their environment (students' discourses, questioning or justifying techniques) elements of schemes founding these techniques. In particular, we focus on her scheme on equation solving with the solve command, her scheme on substitution using the vertical bar "|" command, and the articulation of these two schemes. First, we describe the corresponding commands, as components of the calculator artefact; next, we review the lesson units from this instrumental perspective.

\subsection{The artefact's "solve" and "substitute" commands}

For an appropriate analysis of the observations from a TIG perspective, a clear understanding of the artefact's potentials and constraints for the two main commands, solve and 
Fig. 3 Applying the solve command

\begin{tabular}{|lr|}
\hline solve $\left(a \cdot x^{2}+b \cdot x+c=0, x\right)$ & $x=\frac{\sqrt{b^{2}-4 \cdot a \cdot c}-b}{2 \cdot a}$ or $x=\frac{-\left(\sqrt{b^{2}-4 \cdot a \cdot c}+b\right)}{2 \cdot a}$ \\
\hline solve $\left(a \cdot x^{2}+b \cdot x+c=0, a\right)$ & $a=\frac{-(b \cdot x+c)}{x^{2}}$ \\
\hline solve $\left(x^{7}-x=6, x\right)$ & $x \cdot\left(x^{6}-1\right)=6$ \\
\hline solve $\left(x^{7}-x=6, x\right)$ & $x=1.32917$ \\
\hline
\end{tabular}

substitute, is needed. The following description of these commands and the corresponding techniques aims at this understanding; meanwhile, it also sheds light on the targeted instrumental genesis and scheme development that is invited by the task.

As a starting point, we take the TI- 89 calculator in exact mode setting and in word variable input setting. Indeed, these were the actual calculator settings in the observation. As a remark, it should be noted that the solve and substitute commands can be articulated and combined into more complex (sequences of or nested) commands.

The TI-89 solve command has the following syntax:

$$
\text { solve(equation, unknown) }
$$

- The equation is an algebraic equation which may contain several literal symbols. While entering an equation with more variables, the word input setting requires that the product of two variables, for example $x$ and $y$, needs to be entered with a multiplication sign in between: $x^{*} y$. Without that, $x y$ will be interpreted as one single word variable. The solve command can also be applied to an inequality, but this does not play a role in this case study;

- The unknown is a variable, and can be a word variable;

- The solve command will solve equation with respect to unknown. The result will be one or more solutions of the form unknown=expression, where expression is just a numerical value in case of an equation with unknown as the only variable. Of course, not all equations are solved by the artefact. There is, though, a specific key stroke combination to get approximate, numerical solutions of equations in one single variable.

Figure 3 shows some applications of the solve command.

The TI-89 substitute command has the following syntax:

$$
\text { expression } 1 \mid \text { variable }=\text { expression } 2
$$

- The first expression, expression 1 , can be any algebraic form, including an equation or a formula. In case it contains more than one variable, the same condition for entering products such as " $\mathrm{x} * \mathrm{y}$ " hold as was the case for the solve command;

- The vertical bar ""” is on the key board and is called the "with bar", the "with operator" or the "substitution bar";

- As is the case in the solve command, variable can be a one-symbol variable or a word variable;

- The second expression, expression 2, has to be an expression in the strict sense of the word, which means it should not contain an equal sign ("="). In case of substituting a numerical value for a variable, expression 2 will be a number;

- The "|" operator replaces all instances of variable in expression 1 by expression 2 . The result is a (simplified) expression which does not contain variable anymore. Of course 
Fig. 4 Applying the

"|" command

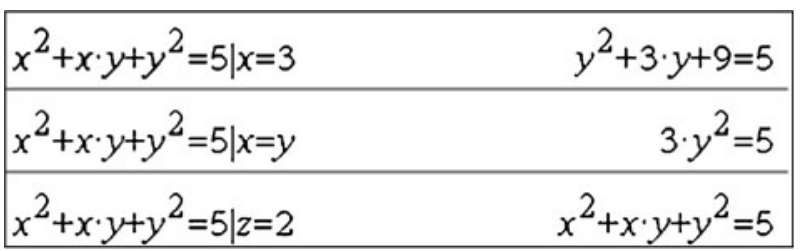

the substitution only makes sense if variable appears in expression 1 . If variable is the only variable in expression 1 , and expression 2 is numeric, the result will be a number.

Figure 4 shows some applications of the "|" command.

\subsection{Equation solving and substitution throughout the case description}

In unit U1, Maria wants to reproduce the graph on the task sheet on the screen of her calculator, even if she is not asked to do so in the task. After some minor technical obstacles, she notices that she needs to substitute values for the parameter, and that the $\mid$ command is appropriate for this. She misses guidelines for the values of $b$, but chooses adequate values and gets the graph. She apparently masters the $\mid$ technique for substituting a set of numerical values and feels very satisfied with the resulting picture.

In unit U2, things get more complicated. She seems to intend to follow the hint in task ii on the zeroes, and therefore enters a solve command. However, she enters an expression instead of an equation, and while trying to correct this, she changes the unknown from $x$ into $b$. Clearly, she does not master the syntax of the solve command; it seems that she does not distinguish expressions and equations, and is confused about the roles of the variables $x$ and $b$. She probably does not understand the idea behind the hint and seems to be oriented towards graphical representations. She is very frustrated and returns to the previous graphing screen where she had been more successful.

In unit U3, Maria once more substitutes a set of numerical values for a parameter like she did in U1. A technical obstacle emerges, concerning the required multiplication sign between the two variables. When this is overcome, she reacts in relieved way: "Yes, that's always me; I never do it completely right."

Unit U4 starts with a syntactically correct application of the solve command. However, it is not clear why Maria wants to solve this equation; the suggestion in the task is to solve $x^{2}+b x+1=0$ with respect to $b$. Also, Maria seems to be confused by the solution being an algebraic expression. She seems to want to go back to numerical values by substituting $b=5$, but strangely enough combines this with a solve command, in which there is no unknown specified. Next she does specify the unknown but makes a mistake with the brackets. She seems to conceptually mix up solve and substitute. Then she substitutes 5 for $b$ manually, and applies the solve command in a syntactically correct way. However, the result is not of any help to her. She seems frustrated again, saying "I'm just too stupid." Technical and conceptual difficulties seem to go hand in hand in this unit.

Unit U5 describes a dialogue with the participating observer. Maria's remark "So you can't solve this" suggests that she does not consider an algebraic expression to be a solution of an equation; in her solve scheme, we guess, a solution is a numerical value. After some misunderstandings on $y$ and $y_{1}$, Maria comes up with the important idea to substitute 0 . The observer helps her by stating that $y$ has to be 0 . This dialogue shows that Maria's scheme for equation solving needs to be expanded with the notion of algebraic rather than just numerical 
solutions. This notion is supported by the solve command, which simply generates such results. Next, Maria continues by manually substituting 0 for $y$ in her previous result. She applies the solve command without technical problems and now seems to accept that the solutions are expressions for $x$ in terms of $b$. When she copies the results with her pen into her paper notebook, however, she hesitates about the length of the square root sign and ends up making it too long. She does not recognize the common structure in the two solutions and is not aware of the two solutions' symmetry in $-b / 2$. Clearly, the representations provided by the artefact obscure these insights. Maria is aware of her limited understanding: "I didn't understand it at all." She is not satisfied with that.

Therefore, in the dialogue in unit U6, Maria wants to better understand the idea behind the task. The first obstacle is the idea that $b$ should have a value, which is true for obtaining graphs, but is not true for obtaining general solutions in terms of the parameter. Next, there is some, partially linguistic, confusion about solving for $b$, express in $b$, take out $b$, and "comma $b$ " in the syntax of the solve command. Finally, Maria's phrase "it's no use to know that it lies between the two zeros if you can't calculate them" shows that she is still struggling with the idea of algebraic expressions as solutions of an equation. This extension of the solve scheme is hard for her.

After the dialogue, Maria wants to substitute $-b / 2$ for $x$ in the function, which is the first algebraic substitution in this case. In U7, she does so, but forgets the brackets around $-b / 2$ before squaring. The idea is fine, but she once again mixes up solve and substitute: while she substitutes, she also applies the solve command. Because of the bracket mistake, she finds $1-b^{2}$ instead of $1-b^{2} / 4$. In U8, she uses her findings to get $\left(-1 / 2 b, 1-b^{2}\right)$ as the equation of the curve through the vertices. She seems to notice that the result should be expressed in terms of $x$, and probably in collaboration with her neighbour, she corrects this and finds the final correct result $y=1-x^{2}$

\subsection{Schemes and techniques for solving and substituting}

We now synthesize the findings concerning Maria's scheme on equation solving, her scheme on substitution, and the articulation of the two. Even if we see some improvements throughout the observations, Maria's scheme on equation solving reveals several conceptual difficulties. Related to the main elements of knowledge at stake in this situation, the most important conceptual elements in this scheme seem to be the following.

1. Knowing that the Solve command can be used to express one of the variables in a parameterized equation in other variables: Maria's scheme seems to see a solution as a numerical value and does not recognize an expression as such.

2. Remembering the TI-89 syntax of the Solve command, that is Solve (equation, unknown): Maria tends to forget to specify the unknown.

3. Knowing the difference between an expression and an equation: Maria several times forgets to add "=0" to an expression to create the corresponding equation.

4. Realizing that an equation is solved with respect to an unknown and being able to identify the unknown in the parameterized problem situation: Maria mixes up the roles of the different literal symbols in the task situation, and is not always able to choose the appropriate unknown.

5. Being able to interpret the result, particularly when it is an expression, and to relate it to graphical representations: For instance, Maria is not able to copy the output correctly into her notebook. 


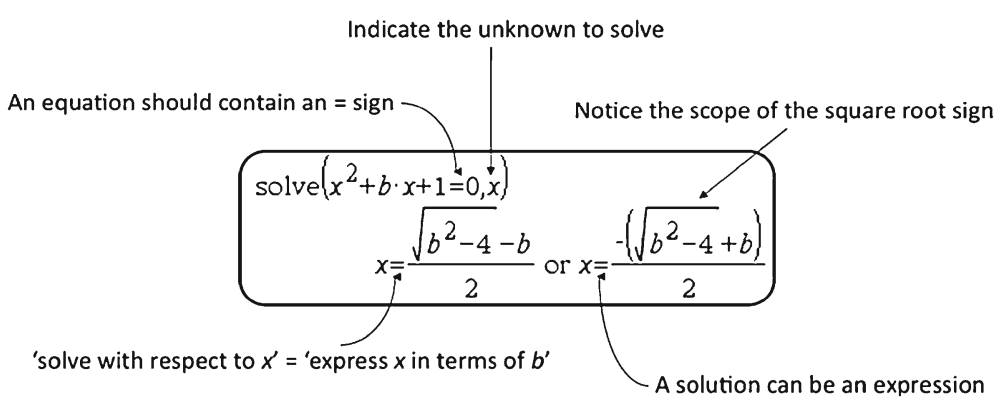

Fig. 5 Conceptual elements related to the application of the solve command

Figure 5 depicts the conceptual aspects of this scheme, clustered around results of the technique on the screen, and helps to identify Maria's difficulties.

Maria's scheme on substitution seems to be fine as far as numerical substitutions are concerned. She is even able to substitute a set of numerical values in order to generate a sheaf of graphs on her calculator screen. However, algebraic substitutions seem to be more troublesome. The only algebraic substitution, $x=-b / 2$, is done by hand, and not without an error. Maria's scheme seems to reveal the following conceptual difficulties:

1. Imagining substitution as "pasting an expression into all instances of a variable": Maria's substitution scheme seems to be limited to numerical substitutions.

2. Remembering the artefact's syntax of the Substitute command and the meaning of the vertical bar symbol in it: Maria is aware of the need of the vertical bar, but is not always able to use it appropriately.

3. Being able to interpret the result, and particularly to accept an equation with two variables as a result: Maria seems to have difficulties with substitution results such as "b=(-x^2-y+1)/x" (unit U5).

Figure 6 depicts the conceptual aspects of this scheme, clustered around the results of the technique on the screen, and helps to identify Maria's difficulties.

The most problematic for Maria seems to be the articulation of her solve and substitute schemes and their integration into a coherent system of instruments. At several points in the observation, Maria seems to mix up the syntax of the two commands, as well as their meanings. Of course, this is related to the mathematical content: the use of parametric functions is quite new to the students, and the changing roles of the different literal symbols,

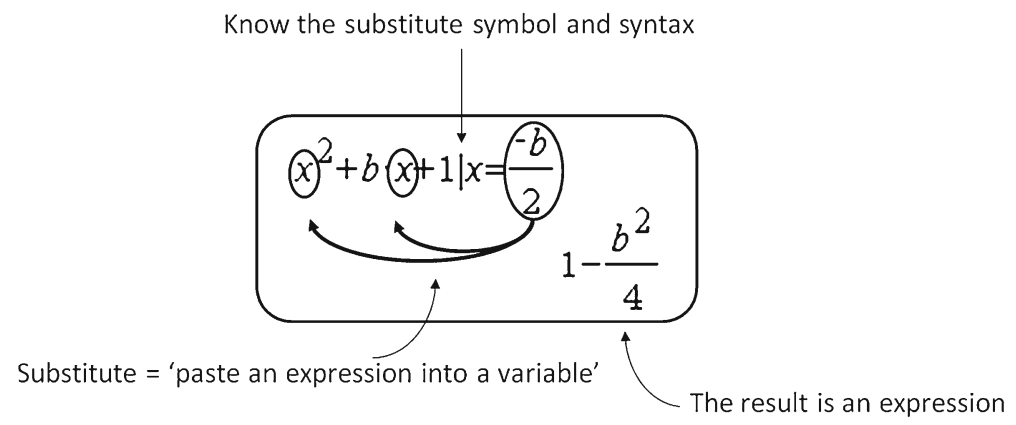

Fig. 6 Conceptual elements related to the "|" command 
in this case $x$ and $b$, are confusing. There seems to be an instrumental genesis to go through, until Maria has an extended understanding of solving equations which contain parameters, of algebraic substitution, of the articulation of the two, and of the techniques to make the artefact do the work for her.

This synthesis shows how an instrumental perspective offers a comprehensive view on the relationships between the student's mathematical understanding, condensed in her schemes, and the ways she uses the artefact commands, through the development of her techniques.

\section{Analysis from the OSA perspective}

The second analysis takes an OSA perspective. The analysis of the protocol focuses on describing Maria's cognitive trajectory as part of a didactic trajectory. This cognitive trajectory is influenced by the interaction with the teacher and her peer student, Ada, as well as by the use of the calculator. The analysis involves identifying the didactic configurations, which are initially studied at two levels:

- The practices used by Maria, to be compared with those expected by the institution;

- The cognitive configuration of primary objects, and its corresponding processes put into play by Maria, compared with the objects and processes that are needed to solve the task. This second level complements the first because it explains the progress of learning.

The aim of this two-level analysis is to determine the effects of the tasks, interactions, and resources on learning. The difficulties that Maria shows in the learning process can be explained in terms of the complexity of the configurations of primary objects required to solve the task, and the network of semiotic functions involved. In this, the particularization and generalization processes play a key role.

An epistemic configuration is conceived as the network of mathematical objects that are put at stake when solving the (sub-)task from an institutional perspective. Due to space limitations we will not describe the epistemic configurations for each task; however, its components will be indicated when describing the students' expected responses.

In this analysis, the symbolic calculator is considered as an object that intervenes in the mathematical practice, in conjunction with other objects. Mastering the commands for solving equations, graphing, etc., however, brings into play configurations of primary objects, and specific processes; this mastery requires specific instruction. Also, the "explosion of digital techniques" (Artigue, 2002) due to the wide potential of the symbolic calculator increases the semiotic complexity of problem solving. Here we apply a detailed analysis of practices, primary objects and processes to units $\mathrm{U} 1$ and $\mathrm{U} 2$; the remaining units will be analyzed in less detail.

5.1 Didactical configuration U1: graphical representation of a family of quadratic functions

\subsubsection{Practices}

With some difficulties Maria gets to produce the graphic representation of the family of functions $y_{1}(x)=x^{2}+b \cdot x+1$ with the calculator TI- 89 , for $b$ ranging from -5 to +5 with step 1. Probably as a result of her practice during previous sessions, Maria can represent the graph of a family of parametric functions, namely: writing algebraic expressions respecting 
the TI-89 syntax rules, assign values to the parameter, adjust the zoom window display and interpret the graphical output as the solution of the task required.

\subsubsection{Cognitive configuration}

In this cognitive configuration, we identify the following primary objects. Propositions do not play a particular role here and therefore are not mentioned.

1) The problem in this configuration is to make a graphic representation of the given family of quadratic functions. The written task does not require this, as such a graph is already provided. However, Maria decides to create it with the calculator. The activity is to graph a finite collection of members of the family, given its symbolic parametric expression. While doing so, Maria introduces personal elements such as the unnecessary use of the letter $a$, which produces confusion because $a$ conventionally denotes the quadratic term coefficient. This activity requires a specific procedure using the calculator, and the use of other primary objects and processes that are discussed below.

2) Linguistic elements include the interpretation of the calculator specific algebraic notation, with its differences from the regular algebraic writing, such as the power notation and the multiplication symbols, and the $\mid$ symbol for assigning a value to a variable. Other symbols involved are $x$ to describe the independent variable, $y_{1}$ for the dependent variable, and $b$ for the parameter. Maria somewhat confuses the use of the letters $b$ and $a$, the latter of which does not intervene in the problem statement. The screen display requires the management of zooming, in addition to interpreting the Cartesian coordinate system.

3) Concepts/definitions include the notion of a family of quadratic functions, $y_{1}(x)=x^{2}+b \cdot x+1$, with the linear term $b$ parameterized; other concepts involved are the notions of function, parameter, value range and step, and list of values.

4) Procedures at stake include typing a family of functions into the TI-89; each function must be named specifically, for example as $y_{1}(x)$. To convert the parameter $b$ into a list of values by adopting a range of values and a step; also, a procedure for setting the calculator screen may be involved.

5) As arguments, the calculator displays a graphical output which is considered the solution of the task, although it does not provide any justification. We would call this an authority argument, referring to the calculator.

The duality particular-general is crucial to understand what a family of functions is, and what a member of the family is. It also plays a key role when the parameter $b$, which is a real variable, by the restrictions of the representation turns into a finite set of values. Initially, $b$ takes a particular value, next it takes any value, and it ends up being a finite set of values in the range $[-5,5]$. To understand that the graph of a quadratic expression, $y=x^{2}+b \cdot x+1$, is a parabola, $b$ must be understood as a particular value, while $x$ and $y$ are variables; to understand that this expression represents a family of parabolas we must assume that $b$ takes any value; to be able to handle the expression with the graphing module of the TI- 89 one must assume that $b$ is a finite set of values.

To understand that the figure materialized on the screen is the graph of a parabola requires two types of idealization, or, in other words, two types of recognizing the presence of nonostensive objects as different from the ostensive objects displayed on the screen: (1) to assume that the set of pixels displayed on the screen represents a part of a perfect parabola and to ignore irregularities in the graph, and (2) to assume that the behaviour of the graph on 
the screen reflects the behaviour of the mathematical function. This reflects the crucial role of the ostensive / non-ostensive duality, mentioned in Section 2, in mathematical activity.

\subsection{Didactical configuration U2}

In unit U2 Maria starts to work on item ii (see Fig. 2) by wanting to find the intersection points of the parabolas with the horizontal axis, which depend on parameter $b$.

\subsubsection{Practices}

Maria should enter solve $\left(\mathrm{x}^{\wedge} 2+\mathrm{b}^{*} \mathrm{x}+1=0, \mathrm{x}\right)$, but instead enters three erroneous expressions: solve $\left(\mathrm{x}^{\wedge} 2+\mathrm{b}^{*} \mathrm{x}+1, \mathrm{x}\right)$; solve $\left(\mathrm{x}^{\wedge} 2+\mathrm{b}^{*} \mathrm{x}+1, \mathrm{x} \mid\right)$; and solve $\left(\mathrm{x}^{\wedge} 2+\mathrm{b}^{*} \mathrm{x}+1, \mathrm{~b}\right)$. In all three cases, her input lacks " $=0$ "; the second and third expression reveal confusion about what is the unknown, and whether or not it is necessary to assign a value to $x$.

\subsubsection{Cognitive configuration}

In this cognitive configuration, we identify the following primary objects.

1) The problem in this configuration is to solve the equation $x^{\wedge} 2+b^{*} x+1=0$, while considering $b$ as a parameter and $x$ the unknown. This procedure makes sense as a first step to find the abscissas (the two solutions of the quadratic equation) of the parabolas' vertices whose locus is to be described.

2) Linguistic elements include specific calculator algebraic notations, and (incorrectly) enter the solve command: solve $\left(x^{\wedge} 2+b^{*} x+1, x\right)$; $\operatorname{solve}\left(x^{\wedge} 2+b^{*} x+1, x \mid\right)$; solve $\left(x^{\wedge} 2+b^{*} x+1, b\right)$.

3) The concepts/definitions include the notion of second degree equation, unknown, parameter, family of quadratic equations, depending on the linear coefficient, $b$ as well as solutions of a quadratic equation, as intersection points with the abscissas axis.

4) The procedures involved are solving an equation with the TI-89 through using the solve command syntax, which requires equating to 0 the algebraic expression, and indicating the unknown, in this case $x$. Trial and error: Maria checks different alternatives of the command.

5) The main arguments in this unit: From the error messages, Maria concludes that she is not applying the command syntactically correctly. She has difficulties with the interpretation of the notion of equation (algebraic expression put equal to zero, indication of the unknown). The calculator provides an authority argument.

From the personal/institutional dimension perspective, Maria does not master the solve command syntax and therefore is not able obtain an expression in terms of $b$. Her attempts suggest that she has difficulties in distinguishing the concepts of equation, function, parameter, variable, unknown, and family of solutions for a parametric equation.

From the institutional point of view we argue that the subtask is complex, as it requires an interpretation of the two solutions for $x$ as family valuesrepresenting the zeros of the quadratic functions family. The complexity of the institutional demand may explain the difficulties, rather than Maria's lack of proficiency in using the calculator.

\subsection{Didactical configuration U3-U6}

We now analyze the practices, primary objects and processes of the units U3-U6 in less detail. 


\subsubsection{Didactical configuration U3}

Maria continues working on the task, reproducing the graphical representation of the family of functions $y=x^{2}+b x+1$. This is complicated by forgetting to put the symbol * between $b$ and $x$ to indicate their multiplication. Maria thinks the error is that $b$ has no value assigned, and she assigns the same values as in the previous session. We observe, therefore, that Maria masters the procedure for assigning values to a list, but the digital language syntax is an obstacle for her. The interaction with the teacher helps her to identify the error; she corrects it and gets the graphics on the screen.

\subsubsection{Didactical configuration U4}

In this unit Maria starts solving the equation $x^{2}+b x+1=0$ with respect to $x$, thus considering $x$ as the unknown and $b$ as parameter. This is a first step towards finding expressions of the parabolas' intersection points with the horizontal axis, which in turn will allow for finding an expression for its vertices. The targeted institutional practice is to enter the expression $\operatorname{solve}\left(\mathrm{x}^{\wedge} 2+\mathrm{b}^{*} \mathrm{x}+1=0, \mathrm{x}\right)$, which results in two values for $x$ in terms of $b$ :

$$
x=\frac{\sqrt{b^{2}-4}-b}{2} \text { and } x=\frac{-\left(\sqrt{b^{2}-4}+b\right)}{2}
$$

This yields two values for $x$ as a function of $b$, the latter thus getting the role of an independent variable. Maria makes several attempts to solve the equation with the symbolic calculator using the solve command, but she does not identify the type of equation to be solved to meet the initial task. First she correctly enters solve $\left(\mathrm{x}^{\wedge} 2+\mathrm{b}^{*} \mathrm{x}+1=\mathrm{y}, \mathrm{b}\right)$, which results in an expression for $b$ as a function of the variables $x$ and $y$. Then she assigns a particular value to $b, b=5$, getting error messages because she does not enter the expressions correctly. Finally, she enters solve $\left(5=\left(-x^{\wedge} 2-y+1\right) / x, x\right)$, obtaining two values for $x$ as a function of $y$, and desperately exclaims: "I don't understand, I am just too stupid. But I don't have a $y$, of course."

Apart from the difficulties that Maria has with handling the solve command syntax, the main problem stems from misunderstanding the problem's meaning: she has not identified the equation to be solved. This is basically the problem of giving meaning to a parametric equation. Maria is familiar with the concept of equation, but not with a family of equations, which requires activating a complex network of semiotic functions (Font \& Contreras, 2008) that allows her to see the particular in the general and vice versa.

\subsubsection{Didactical configuration U5}

Maria tries to solve an equation that is not expected from the institutional point of view, considering that $b$ is the unknown: $\operatorname{solve}\left(\mathrm{y}=\mathrm{x}^{\wedge} 2+\mathrm{b}^{*} \mathrm{x}+1, \mathrm{~b}\right)$. She enters this equation correctly and gets a solution for $b: \mathrm{b}=\left(\mathrm{x}^{\wedge} 2-\mathrm{y} 1\right) / \mathrm{x}$. With the teacher's help she understands that a value 0 should be assigned to $y$, and that $x$ is the unknown. She now types in the command correctly, solve $\left(\mathrm{b}=\left(\mathrm{x}^{\wedge} 2-0+1\right) / \mathrm{x}, \mathrm{x}\right)$, and finally obtains the two expected solutions for $x$.

Maria writes the expression of the vertex coordinates and the midpoint $-1 / 2 b$ of the two solutions in her notebook, but claims not to understand anything she has done: "I did work through Section 9 but I didn't understand it at all." 
In this didactical configuration we observe a mixed pattern of guided discovery in which the teacher's intervention, reporting that $y$ is zero, is crucial for Maria getting the two values of $x$. This happens, however, in a complicated way that does not facilitate the understanding of the situation. Maria continues without giving meaning to the problem, to the roots of the equation that she solved in terms of $b$, and the average of the two roots obtained.

\subsubsection{Didactical configuration U6}

The teacher explains the task again, saying that the equation needs to be solved for $x$. Maria insists that it is necessary to assign a value to $b$, showing that she is still thinking of the particular case; she does not understand how to work with the general task requirements by using a literal symbol operating as a parameter. During the dialogue between Maria and the teacher, the teacher phrases (or imposes?) the rules for the use of generic elements in the mathematical work.

The teacher explains that Maria may assign a value to $b$, but in this case it would be a single value, and that not assigning a value to $b$, in fact provides all values at once. Assigning a value to $b$ is only necessary to draw a graph.

Maria insists on considering $b$ as the unknown which needs to be found. The teacher explains that we need $x$ to find the zeros of the function, but as we do not know $b$, we get something in terms of $b$. Maria still does not understand the meaning of the task, the calculations and the resulting two values of $x$ produced by the calculator:

Maria: But it's no use to know that it [the vertex] lies between the two zeros if you can't calculate them.

Teacher: You get something that contains the $b$, and you can continue the calculation with that.

The didactical phenomena in this configuration are rich. We see that the graphic representation of functions with the calculator, which requires assigning particular values to the parameter, is still an obstacle for the general symbolic manipulation of the parameter. The task's complexity leads to a somewhat forced intervention by the teacher to introduce the rules for the use of generic elements, assuming a clear normative pattern of interaction.

Understanding the use of parameters requires the activation of a network of semiotic functions that allows seeing the particular in the general and vice versa. However, activation and development of such a network involves a language "game" governed by meta-epistemic rules (Font \& Contreras, 2008; Godino, Font, Wilhelmi \& Castro, 2009). The didactical configuration U6 provides an example of how the teacher starts to introduce the features of this language game, as well as of the difficulties faced by the students, in this case Maria, to engage in it.

\section{Comparing and contrasting the two analyses}

The presentation of the theoretical concepts and principles in TIG and OSA (sections 2.2 and 2.3) as well as the resulting analyses of the episode from these perspectives (sections 4 and 5) allows us to better understand the principles of both theories as well as the insights they offer. In the frame of networking theories, we now wonder what a joint analysis in terms of comparing and contrasting the two analyses leads to.

In the episode students are asked to find an equation that describes the locus of the vertices of a parametric family of parabolas using a symbolic calculator. Table 1 summarizes and merges the results of the TIG and OSA analyses. It shows that the insights in Maria's 
Table 1 Overview of TIG and OSA analysis results

TIG analysis results

OSA analysis results

- Describes the characteristics of techniques for using the artefact and the commands solve and substitute in particular, and thus provides insight in the possible and targeted process of instrumental genesis.

- Shows that Maria masters the substitution technique for producing graphs of functions through assigning particular values to $b$.

- Shows that Maria does not master the solve command syntax by not distinguishing between expression and equation and by not recognizing an expression as a solution.

- Shows that Maria mixes up and confuses the solve and substitute commands.

- Identifies the interrelated technical and conceptual difficulties in implementing the commands solve and substitute.

- Identifies the main elements of Maria's conceptual schemes related to the techniques of the solve and substitute commands, including their conceptual difficulties.
- Describes the institutional practices to solve the required task and the configuration of objects and processes involved, and this way shows the ontosemiotic complexity of these configurations.

- Describes Maria's cognitive trajectory as part of the didactic trajectory, including practices, objects and processes mobilized in interaction with the teacher and the calculator.

- Describes Maria's conflicts of meaning during the learning process and their solutions (or non-solutions). First, it reveals the distinction between ostensive and non-ostensive objects, and extensive-intensive objects; next, it identifies the conceptual distinction between an ordinary equation and a parametric equation.

- Helps to understand the learning difficulties through the onto-semiotic complexity of the task, which has not been taken into account adequately in the instructional process: the use of generic elements, the process of generalization, the notions of parametric equation and family of parametric functions.

behaviour provided by TIG and OSA, respectively, are largely complementary. The OSA analysis of units U3-U6 is made in terms of practices, which simultaneously identify relevant objects. It is similar to the TIG analysis in terms of techniques, which also identify conceptual elements. The OSA didactical look complements TIG's cognitive view. The instrumental genesis of the schemes of solving and substitution, that is the mastering of gestures and knowledge involved, requires the implementation of a sequence of didactical configurations to promote the scheme generation.

The TIG basically explains Maria's learning processes and the difficulties that emerge in terms of instrumental genesis: the development and coordination of techniques and schemes, in which the possibilities and constraints of the artefact play a decisive role. The OSA describes Maria's learning difficulties through the onto-semiotic complexity of the activity needed to solve the tasks. Both theories provide explanatory causes of the student's difficulties that can be coherently articulated. The TIG explanation focuses on the subject's cognitive development and allows for predicting the student's performance in similar future tasks. As long as Maria does not develop appropriate instrumentation schemes, it is likely that mistakes will continue to appear. The OSA provides an explanation of why Maria's schemes have not been developed: the onto-semiotic complexity of the task triggers conflicts that have not been satisfactorily resolved in the interactions that take place in the teachinglearning trajectory. This has hindered Maria in her development of the schemes.

\section{Comparing and contrasting the two theories}

In this section we compare and contrast the theoretical frameworks of TIG and OSA. The two analyses and their overview provided in the previous section clearly reveal the differences between the two frameworks. This, of course, is not a surprise: whereas TIG basically 
takes a cognitive stance towards learning processes in which the use of artefacts plays an important role, OSA takes a wider perspective and incorporates a set of conceptual elements for different facets of mathematics education.

According to Radford (2008), essential elements of a theory include principles, methods, and paradigmatic research questions. In the following, these three elements guide the comparison and contrasting of the two approaches.

\subsection{Comparing and contrasting principles}

Table 2 provides an overview of the main principles of TIG and OSA, as described in sections 2.2 and 2.3. A first method to compare and contrast the two frameworks is to try to establish links between the two columns. As an example, below we elaborate on the links between technique and mathematical practice, between scheme and cognitive configuration, and between instrumental genesis and cognitive trajectory.

\subsubsection{Technique and mathematical practice}

In TIG the technique is presented as the observable part of the student's mental scheme used for solving a given type of task, having both a pragmatic and an epistemic value. In the OSA a mathematical practice is understood as a sequence of actions governed by rules and oriented towards a goal. One of the primary objects governing the mathematical practice is the procedure, which is understood as a rule indicating the steps to follow to carry out the practice, or a part of the practice.

If we compare TIG's techniques and OSA's mathematical practices and procedures, it seems that the level addressed by the notion of technique is somewhere between the mathematical practice level and the procedural level. A mathematical practice can be understood as a general technique, whereas a procedure seems too limited to capture the notion of a technique with not only the pragmatic but also the epistemic meaning and the relation with the scheme. The notion of mathematical practice is somewhat broader than the technique because it also includes the application of conceptual, propositional and argumentative rules, that is, the various elements of a configuration. Furthermore, the notion of technique is more focusing on the use of artefacts.

We conclude that the notions of procedure, technique, and mathematical practice can be articulated to jointly provide a full view on students' activity with artefacts.

\subsubsection{Scheme and cognitive configuration}

The above analysis suggests that the notions of scheme and cognitive configuration can be connected. In TIG, a scheme (of instrumented action) is made of gestures for using the given

Table 2 TIG and OSA principles

\begin{tabular}{ll}
\hline TIG principles & OSA principles \\
\hline - Instrumental genesis & - Mathematical practice \\
- Artefact and instrument & - Cognitive and epistemic configuration of primary objects \\
- Instrumentation and instrumentalisation & - Mathematical processes \\
- Scheme and technique & - Meaning and semiotic function \\
- Instrumental orchestration & - Didactical configuration, cognitive trajectory \\
\hline
\end{tabular}


artefact, rules of action, and conceptual elements, both guiding the activity, and developed by this activity. OSA's cognitive configuration is a network of primary objects involved in the systems of personal practices that students carry out during the implementation of the epistemic configuration. The two notions share a focus on intertwining 'thinking and doing' in the student's mathematical activity while solving a particular task or a type of tasks.

There are also some differences. The cognitive configuration is linked to a particular task instance, while the scheme is related to types of tasks and, in that perspective, can be seen as a mental emergent of a type of cognitive configuration rather than as a particular cognitive configuration. Furthermore, the notion of cognitive configuration includes a typology of objects and processes which extends the scheme conceptualist view. In that sense the cognitive configuration complements the scheme and provides a structure for the scheme put into action in a given situation. The above analysis has shown that the context in which a scheme is implemented can be described in terms of cognitive configuration. The two notions are distinct, but complementary, with the scheme being more directly related to the gestures of using an artefact and the cognitive configuration taking a larger perspective.

\subsubsection{Instrumental genesis and cognitive trajectory}

The OSA notion of cognitive configuration relates to the student's cognitive trajectory, which is a sequence of cognitive configurations. This is done because the OSA is oriented towards teaching, and cares about the design of sequences of tasks. The notion of instrumental genesis is crucial for TIG. It is described as the process of an artefact becoming part of an instrument in the hands of a user, through the development of schemes and techniques. The notions of instrumental genesis and cognitive trajectory share a focus on learning processes and trajectories over time, and both stress the importance of cognitive development, guided by instructional activity. Again, the analyses reveal that instrumental genesis is more focused on a precise description of the development of schemes and techniques over time, whereas the notion of cognitive trajectory takes a broader perspective and describes the sequence of cognitive configurations of primary objects during the teaching sequence.

The notions of artefact and instrument could be assimilated in the OSA perspective. The artefact can be seen as a material or symbolic object acting in mathematical practice together with other primary objects. Instrument could be seen as a pair consisting of the artefact used in a practice and the associated cognitive configuration. In this way, TIG notions might enrich OSA; in this case, this would be in line with the above remarks on similarities between scheme and cognitive configuration.

In a similar way, the description and distinction of instrumentation and instrumentalisation processes within TIG can be seen as "mega-processes" in the OSA perspective. The instrumentation and instrumentalisation processes include processes such as generalizationparticularization, materialization-idealization, and composition-division, linked to specific mathematical activity in which the artefacts intervene. Instrumentation and instrumentalisation are personalization processes in which the subject develops schemes and enriches artefacts. This personalization, however, does not take place in an individual and autonomous way but requires expert intervention that presents and explains the rules for the artefact's use, which is a process of institutionalization.

\subsection{Comparing and contrasting methods}

Table 3 provides an overview of the main methods of TIG and OSA, as they appear in the analyses presented above. A TIG analysis may start with an a priori analysis of artefacts involved 
and of the targeted schemes and techniques to be developed, as well as of the role that the tasks play in this instrumental genesis process. Next, the analysis focuses on the student's instrumental genesis while using the artefact to solve the task. Ideally speaking, this requires data over a more extended period of time than the episode from two lessons presented in this article. Finally, the method aims at describing learning in terms of the development and articulation of schemes and techniques, including learning difficulties in terms of limited instrumental genesis.

The OSA analysis may start with an a priori analysis of the complexity of the task. The episode is broken down into didactical configurations, each focusing on a subtask. The student's mathematical activity is analyzed in terms of the complexity of the practices, configurations of objects and processes. Also, it is considered whether the interactions between the teacher, student and artefacts have taken into account the complexity and whether they have resolved the conflicts of meaning. Concerning the type of data needed, OSA analysis requires the task statement and expected solution (epistemic analysis), the students' responses (cognitive analysis), and the transcripts of the interactions between teachers, students and media (instructional analysis).

Comparing the two methods, we notice that TIG provides methodological elements for the analysis of mathematical activity supported by artefacts while OSA provides a global model of mathematical activity. Both models can complement each other, the OSA introducing the notion of artefact as an object in mathematical practices, and the TIG expanding its model of analysis of mathematical activity. As already stated above, the process of instrumental genesis can be analyzed using the notion of cognitive trajectory.

When comparing and articulating theories with a methodology based on the analysis of learning episodes, the limitations of the empirical material that can be used, given the time and space constraints, is problematic. This paper's empirical data certainly are limited: it consists of only one episode of Maria using a symbolic calculator to solve a task. A networking methodology that complements the analysis of a particular episode by the direct comparison of the theories' problems, principles and methodologies in such cases can help to overcome these limitations (e.g., see Godino, Font, Contreras and Wilhelmi (2006) for such a methodology to analyze different French mathematics education theories).

The different theories and their methodologies lead to different demands on the empirical data. In this case, the TIG analysis, which primarily focuses on instrumental genesis, defined as the development of schemes and techniques over time, was hindered by the limitations of the data taken into consideration. The OSA analysis would be more complete if data on the group discussion and on the teacher's explanation after the episode had been available. Likewise, the interpretation of learning conflicts would benefit from data on Maria's

Table 3 TIG and OSA methods

\begin{tabular}{ll}
\hline TIG methods & OSA methods \\
\hline - To identify and describe the artefacts in play & $\begin{array}{l}\text { To a priori analyze the complexity of the tasks } \\
\text { - To a priori describe targeted }\end{array}$ \\
$\begin{array}{l}\text { techniques and schemes } \\
\text { - To break down the learning process into } \\
\text { didactic configurations }\end{array}$ \\
$\begin{array}{ll}\text { instrumental genesis } & \text { - To carry out an onto-semiotic analysis of } \\
\text { - To analyze the students actual instrumental } & \text { cognitive configurations. } \\
\text { genesis over time, including the difficulties } & - \text { To analyze the interactions around conflicts } \\
\text { and obstacles that may hinder it } & \text { of meaning. } \\
\text { - To explain the learning and its eventual difficulties } & - \text { To explain emerging difficulties, obstacles and } \\
\text { in terms of the development and articulation } & \text { conflicts, while taking into account the task } \\
\text { of techniques and schemes over time } & \text { complexity and the classroom interaction }\end{array}$ \\
\hline
\end{tabular}


previous mastery of the calculator and on the treatment of the algebraic concept of parameter in the previous lessons, which were not available.

\subsection{Comparing and contrasting paradigmatic research questions}

Table 4 provides an overview of the main research questions of TIG and OSA, as they emerge from the analyses of the episode presented in this article. Again, these paradigmatic questions are complementary rather than contradictory. TIG's central theme is the description of the development of cognitive schemes for using the artefacts. The central issues in OSA are to describe the onto-semiotic complexity of the tasks and to explain the learning difficulties while analyzing whether the instructional process takes into account this complexity. Both theories are interested in institutional mathematical practices, and make $a$ priori analyses of the mathematical activity needed to solve the proposed task.

In the case of OSA the onto-semiotic and anthropological assumptions invite questions phrased in terms of the pair practice - configuration of objects and processes, in their duality of institutional and personal. In the case of TIG the epistemic model emphasizes the techniques, which reflect cognitive schemes, defined as unobservable mental entities. In both cases, students' techniques (in the case of TIG), and the practices and cognitive configurations (in the case of OSA) are compared with an a priori formulated institutional reference. Both theories are concerned with characterizing the student's learning and identifying the difficulties and obstacles that may play a role, and take a dynamic perspective while studying development over time in terms of instrumental genesis and cognitive trajectory, respectively.

\section{Conclusion}

The central question addressed in this paper is: What does networking instrumental and ontosemiotic approaches as lenses for didactical analysis add to the results of the separate analyses and how can the results be compared and contrasted? As an answer we now reflect on the benefits and pitfalls of applying two lenses for the purpose of theoretical reflection and advancement.

As an answer, the direct confrontation of the two lenses by comparing and contrasting the two separate frameworks and the corresponding analyses, as they were presented in sections 6 and 7, show how the joint analysis indeed led to a more complete view of the

Table 4 TIG and OSA paradigmatic research questions

\begin{tabular}{|c|c|}
\hline TIG questions & OSA questions \\
\hline $\begin{array}{l}\text { - What are potentials and constraints of the artefact } \\
\text { while solving parametric equations and } \\
\text { representing parametric families of functions? } \\
\text { - Which techniques and schemes do the students } \\
\text { develop while solving the task using the artefact? } \\
\text { - What process of instrumental genesis } \\
\text { can be observed in the techniques used } \\
\text { and their justification? } \\
\text { - How are the different schemes and techniques } \\
\text { articulated while solving the task? } \\
\text { - Which difficulties and obstacles appear } \\
\text { in the process of instrumental genesis? }\end{array}$ & $\begin{array}{l}\text { - What are the institutional mathematical practices } \\
\text { and the configurations of object and processes } \\
\text { therein required to solve the mathematical task? } \\
\text { - Which mathematical practices, objects and processes } \\
\text { brings the student into play in the sequence of } \\
\text { subtasks that make up the observed episode? } \\
\text { - Which personal practices, objects and processes } \\
\text { involved, performed by the student, are } \\
\text { valid from the institutional perspective? } \\
\text { - What are the causes of the difficulties, } \\
\text { obstacles and conflicts of learning? } \\
\text { - What is the role of classroom interaction to overcome } \\
\text { these difficulties, obstacles and conflicts of learning? }\end{array}$ \\
\hline
\end{tabular}


phenomenon under study. The two approaches shared some conclusions and complemented each other on other points. Together, this provided a better understanding of the episode that was analyzed. Also, it informed further theoretical development and articulation, such as the identification of similarities in theoretical notions (Section 7.1) and the idea to include the notion of artefact into the OSA framework. Overall, the two lenses led to comparable and complementary rather than conflicting results. The findings were often in agreement with each other, but offered different levels of elaboration or different, complementary foci that beg for articulation. For example, the central role of the artefact supporting mathematical activity in TIG relates to the role of primary objects in OSA, even if the latter takes a more general view on student activity. The TIG concept of artefact can be assimilated in the OSA perspective as a primary object (material or symbolic) involved in mathematical practice together with other primary objects such as problems, definitions, procedures, propositions, arguments.

As an agenda beyond the direct comparison of the two lenses, we set out to investigate the benefits and pitfalls of such a joint analysis for the purpose of theoretical reflection and advancement. Do the recommendations by Prediger, Bikner-Ahsbahs and Arzarello (2008) on comparing and contrasting theoretical perspectives indeed lead to fruitful theoretical reflection? The answer to this question, according to our experience, is positive. The application of the OSA and TIG theoretical tools to the same episode has allowed us to better understand the meaning, use and scope of these lenses. Making ourselves understood and to understand the theories of others, one of the strategies that Prediger, Bikner-Ahsbahs and Arzarello (2008) describe for comparison and articulation of theories, indeed led to a better description and articulation of the affordances and constraints of the lenses, even if a real mutual understanding is quite an effort to achieve. For example, it was helpful to explain explicitly that OSA is a theoretical approach to mathematics education that incorporates a set of conceptual notions for different facets involved in the teaching and learning of mathematics, whereas TIG has a strong cognitive orientation towards how the learning and teaching of mathematics is mediated by the use of artefacts. Also, the idea of comparing and contrasting theoretical notions and findings from the analysis proved to be fruitful. As a methodology to do so is not yet well-established, Radford's (2008) description of theory was helpful to frame this activity. Also, we consider the team members' expertise in the theoretical approaches as a crucial prerequisite for the networking to be successful. As an overall conclusion, we do believe that theoretical advancements indeed may benefit from such networking of theory activities, we recommend its methodology to be further elaborated, and believe our experience may provide a contribution to that.

Acknowledgement We thank the reviewers of Educational Studies in Mathematics for their valuable comments on the earlier version of this article. The research work reported in this article was partly carried out in the frame of the projects EDU2010-1494 and EDU 2009-08120(MICINN).

Open Access This article is distributed under the terms of the Creative Commons Attribution License which permits any use, distribution, and reproduction in any medium, provided the original author(s) and the source are credited. 


\section{Appendix: case description and analysis units}

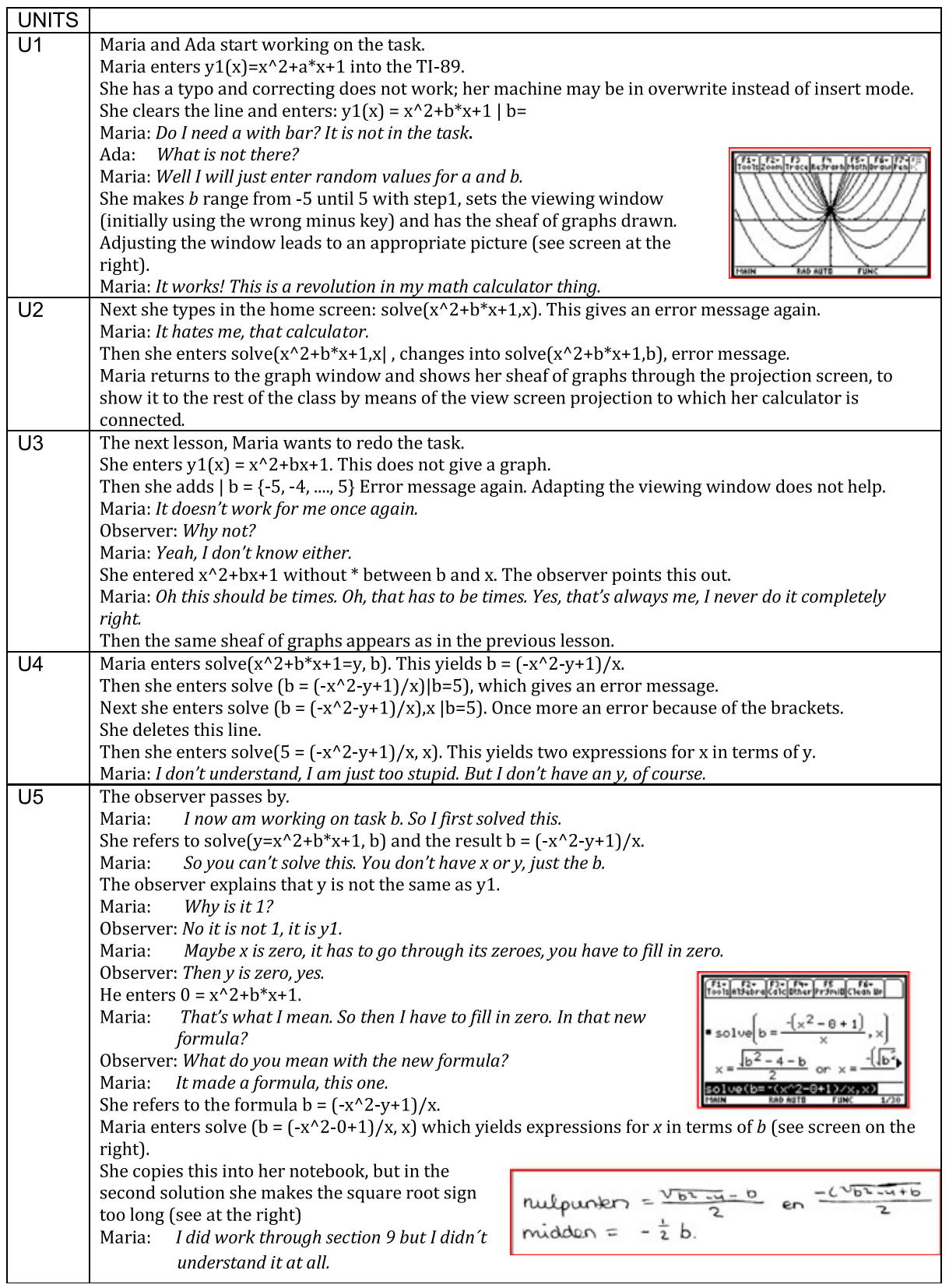




\begin{tabular}{|c|c|}
\hline \multirow[t]{2}{*}{ U6 } & $\begin{array}{l}\text { The observer explains the task once again and says that one has to solve the equation to } \mathrm{x} \text {. } \\
\text { Maria: But then you have to fill in a value for b? } \\
\text { Observer: You can do that, but then you pick out one. But as long as you don't fill in a value for b, you do it } \\
\text { in fact for all values at once.. } \\
\text { Maria: Oh so that's not necessary. } \\
\text { Observer: No, only if you want to draw a graph. } \\
\text { Maria: So you do so to say } 0=\text { and then comma b, because you have to solve it for } b \text {. } \\
\text { Observer: Well no. } \\
\text { Maria: But you had to express in b? } \\
\text { Observer: Yes but you want to know the zeroes, you want to know the } x \text {, but because you don't know bet, } \\
\text { Maria: } \quad \text { I already thought so, I thought you had to take out b. } \\
\text { Observer: No, you have to take out } x \text {. } \\
\text { Maria: But how do you get the zeros then? } \\
\text { Observer: Then you say } x^{2}+b x+c=0 \text {. } \\
\text { Maria: But it's no use to know that it [the vertex] lies between the two zeros if you can't calculate them. } \\
\text { Observer: You get something that contains the b, and you can continue the calculation with that. }\end{array}$ \\
\hline & $\ldots .$. \\
\hline U7 & $\begin{array}{l}\text { Maria continues after the observer left and enters solve }\left(\mathrm{y}=-0.5^{*} \mathrm{~b}^{\wedge} 2+\mathrm{b}^{*}-0.5^{*} \mathrm{~b}+1, \mathrm{y}\right) \text { in order to } \\
\text { substitute }-0.5 \mathrm{~b} \text {, but she forgets the brackets needed in }\left(-0.5^{*} \mathrm{~b}\right)^{\wedge} 2 \text {. This yields } y=1-b^{2} \text {. }\end{array}$ \\
\hline U8 & $\begin{array}{l}\text { For question c, Maria writes down in her notebook that the extreme points have coordinates }\left(-1 / 2 b, 1-b^{2}\right) \\
\text { and concludes that the equation of the curve through the extreme points was } y=\left(1-b^{2}\right)^{*} x-1 / 2 b \text {. } \\
\text { However, probably with the help of her neighbour, she corrected her error and ended up with the right } \\
\text { formula for the curve through the vertices: } y=1-x^{2} \text {. }\end{array}$ \\
\hline
\end{tabular}

\section{References}

Artigue, M. (2002). Learning mathematics in a CAS environment: The genesis of a reflection about instrumentation and the dialectics between technical and conceptual work. International Journal of Computers for Mathematical Learning, 7, 245-274.

Artigue, M., Cerulli, M., Haspekian, M., \& Maracci, M. (2009). Connecting and integrating theoretical frames: The TELMA contribution. International Journal of Computers for Mathematical Learning, 14, $217-240$.

Bikner-Ahsbahs, A., \& Prediger, S. (2010). Networking of theories — an approach for exploiting the diversity of theoretical approaches. In B. Sriraman \& L. English (Eds.), Theories of mathematics education: Seeking new frontiers (pp. 483-506). New York: Springer.

Chevallard, Y. (1999). L'analyse des pratiques enseignantes en théorie anthropologique du didactique. [The analysis of teachers' practices in the anthropological theory of didactics]. Recherches en Didactique des Mathématiques, 19, 221-266.

Drijvers, P. (2003). Learning algebra in a computer algebra environment. Design research on the understanding of the concept of parameter. Utrecht: Freudenthal Institute.

Drijvers, P., Doorman, M., Boon, P., Reed, H., \& Gravemeijer, K. (2010). The teacher and the tool: Instrumental orchestrations in the technology-rich mathematics classroom. Educational Studies in Mathematics, 75(2), 213-234.

Eco, U. (1976). Tratado de semiótica general. [A theory of semiotics]. Barcelona: Lumen.

Even, R., \& Schwarz, B. (2003). Implications of competing interpretations of practice for research and theory in mathematics education. Educational Studies in Mathematics, 54(2-3), 283-313.

Font, V., \& Contreras, A. (2008). The problem of the particular and its relation to the general in mathematics education. Educational Studies in Mathematics, 69, 33-52.

Font, V., Godino, J. D., \& Gallardo, J. (2012). The emergence of objects from mathematical practices. Educational Studies in Mathematics, Online First. doi:10.1007/s10649-012-9411-0.

Godino, J. D., \& Batanero, C. (1998). Clarifying the meaning of mathematical objects as a priority area of research in mathematics education. In A. Sierpinska \& J. Kilpatrick (Eds.), Mathematics education as a research domain: A search for identity (pp. 177-195). Dordrecht: Kluwer Academic Publishers.

Godino, J. D., Batanero, C., \& Font, V. (2007). The onto-semiotic approach to research in mathematics education. ZDM, The International Journal on Mathematics Education, 39(1-2), 127-135.

Godino, J. D., Font, V., Contreras, A., \& Wilhelmi, M. R. (2006). Una visión de la didáctica francesa desde el enfoque ontosemiótico de la cognición e instrucción matemática. [A view of the French didactics from the onto-semiotic approach to cognition and instruction]. Revista Latinoamerica de Investigación en Matemática Educativa, 9(1), 117-150.

Godino, J. D., Font, V., Wilhelmi, M. R., \& Castro, C. (2009). Aproximación a la dimensión normativa en didáctica de las matemáticas desde un enfoque ontosemiótico. [An approach to 
the normative dimension in mathematics education from an onto-semiotic viewpoint]. Enseñanza de las Ciencias, 27(1), 59-76.

Godino, J. D., Font, V., Wilhelmi, M. R., \& Lurduy, O. (2011). Why is the learning of elementary arithmetic concepts difficult? Semiotic tools for understanding the nature of mathematical objects. Educational Studies in Mathematics, 77(2/3), 247-265.

Guin, D., \& Trouche, L. (1999). The complex process of converting tools into mathematical instruments: The case of calculators. International Journal of Computers for Mathematical Learning, 3, 195-227.

Hjelmslev, L. (1943). Prolegomena to a theory of language. Madison: University of Wisconsin Press.

Hoyles, C., \& Noss, R. (2003). What can digital technologies take from and bring to research in mathematics education? In A. J. Bishop, M. A. Clements, C. Keitel, J. Kilpatrick, \& F. Leung (Eds.), Second international handbook of mathematics education (Vol. 1, pp. 323-349). Dordrecht: Kluwer Academic Publishers.

Lagrange, J.-B. (2000). L'intégration d'instruments informatiques dans l'enseignement: une approche par les techniques. [The integration of technological instruments in education: An approach by the techniques]. Educational Studies in Mathematics, 43, 1-30.

Lagrange, J.-B., Artigue, M., Laborde, C., \& Trouche, L. (2003). Technology and mathematics education: A multidimensional study of the evolution of research and innovation. In A. Bishop, M. A. Clements, C. Keitel, J. Kilpatrick, \& F. K. S. Leung (Eds.), Second international handbook of mathematics education (pp. 239-271). Dordrecht: Kluwer Academic Publishers.

Lagrange, J.-B., \& Psycharis, G. (2011). Combining theoretical frameworks to investigate the potential of computer environments offering integrated geometrical and algebraic representations. Paper presented at ICTMT10 conference, July 8th, 2011, Portsmouth, UK.

Leung, A. (2008). Dragging in a dynamic geometry environment through the lens of variation. International Journal of Computers for Mathematical Learning, 13, 135-157.

Maier, H., \& Steinbring, H. (1998). Begriffsbildung im alltäglichen Mathematikunterricht-Darstellung und Vergleich zweier Theorieansätze zur Analyse von Verstehensprozessen. [Concept development in everyday mathematics education: Presentation and comparison of two theoretical approaches to the analysis of the process of understanding]. Journal für Mathematik-Didaktik, 19(4), 292-329.

Peirce, C. S. (1978). The collected papers of Charles Sanders Peirce. Cambridge: The Belknap Press of Harvard University Press.

Prediger, S., Arzarello, F., Bosch, M., \& Lenfant, A. (Eds.) (2008). Comparing, combining, coordinatingnetworking strategies for connecting theoretical approaches. ZDM, The International Journal on Mathematics Education, 40(2), 163-327.

Prediger, S., Bikner-Ahsbahs, A., \& Arzarello, F. (2008). Networking strategies and methods for connecting theoretical approaches: First steps towards a conceptual framework. ZDM, The International Journal on Mathematics Education, 40(2), 165-178.

Rabardel, P. (2002). People and technology - a cognitive approach to contemporary instruments. Retrieved December 15, 2011, from http://ergoserv.psy.univ-paris8.fr/Site/default.asp?Act_group=1.

Radford, L. (2008). Connecting theories in mathematics education: Challenges and possibilities. ZDM, The International Journal on Mathematics Education, 40(2), 317-327.

Trouche, L. (2000). La parabole du gaucher et de la casserole à bec verseur: Étude des processus d'apprentissage dans un environnement de calculatrices symboliques. [The parable of the left and the pot with a spout: A study of the learning process in an environment of symbolic calculators]. Educational Studies in Mathematics, 41, 239-264.

Trouche, L. (2004). Managing complexity of human/machine interactions in computerized learning environments: Guiding students' command process through instrumental orchestrations. International Journal of Computers for Mathematical Learning, 9, 281-307.

Trouche, L., \& Drijvers, P. (2010). Handheld technology: Flashback into the future. ZDM, The International Journal on Mathematics Education, 42(7), 667-681.

Vergnaud, G. (1996). Au fond de l'apprentissage, la conceptualisation. [At the heart of the learning, the conceptualisation]. In R. Noirfalise \& M.-J. Perrin (Eds.), Actes de l'école d'été de didactique des mathématiques [Proceedings of the summer school in didactics of mathematics] (pp. 174-185). Clermont-Ferrand: IREM, Université Clermont-Ferrand 2.

Verillon, P., \& Rabardel, P. (1995). Cognition and artefacts: A contribution to the study of thought in relation to instrument activity. European Journal of Psychology of Education, 9(3), 77-101.

Wittgenstein, L. (1953). Philosophical investigations. Oxford: Blackwell Publisher. 